\title{
Missionários franciscanos em Goa
}

\author{
FARIA, Patricia Souza de. A conquista das almas do oriente: \\ franciscanos, catolicismo e poder colonial português em Goa \\ (1540-1740). Rio de Janeiro: 7 Letras, 2013.
}

\section{Rubens Leonardo Panegassi ${ }^{1}$}

Patricia Souza de Faria é uma jovem historiadora que tem se dedicado ao estudo da presença de missionários católicos nas conquistas portuguesas do Oriente. Patricia é doutora em História pela Universidade Federal Fluminense (2008), tendo realizado estágio de pesquisa no Instituto Superior de Ciências do Trabalho e da Empresa, em Portugal. Com mais de uma dezena de artigos publicados, pode-se dizer que a autora é uma referência importante a todos os investigadores que pretendem se dedicar às questões relativas ao Oriente Português na Época Moderna.

Tradicionalmente, o tema da presença portuguesa no Oriente ao longo da Época Moderna apresenta-se associado a grandes nomes da historiografia, tais como Charles $\mathrm{R}$. Boxer, Luís Filipe F. R. Thomaz e Sanjay Subrahmanyam. Entretanto, vale notar que o vigor e a capacidade de renovação desse campo é notável, sobretudo na produção historiográfica de nomes que tem alcançado visibilidade, tais como Ana Paula M. Avelar e Ines G. Zupanov. Por sua vez, no Brasil, o assunto ganhou aderência como objeto de estudo, evidente nos trabalhos de pesquisadoras como Célia Cristina da Silva Tavares e Andréa Carla Doré. Com efeito, Patricia Souza traz efetiva contribuição à consolidação deste campo entre os investigadores brasileiros, além de sanar uma grande lacuna no âmbito dos estudos sobre o tema das missões na primeira modernidade, tendo em vista que a autora se debruça sobre o papel dos franciscanos neste processo, uma ordem ainda pouco estudada, a despeito dos esforços de Alan Strathern e Ângela B. Xavier.

Apresentado originalmente como tese de doutorado, o livro traz substanciais modificações em relação ao trabalho original, visíveis no acréscimo de todo um capítulo, bem como na relevância dada aos franciscanos em sua relação com o Arcebispado de Goa. Além, evidentemente, da dilação do recorte temporal do estudo, notável nas modificações adicionadas ao segundo capítulo, que enfocam o início do século XVIII, ao passo que a

\footnotetext{
${ }^{1}$ É graduado em História pela Universidade de São Paulo (2004) e graduado em Comunicação Social pela Fundação Armando Álvares Penteado (1999). É mestre (2008) e doutor (2013) em História Social pela Universidade de São Paulo. Atualmente é professor de História Moderna e Contemporânea do Departamento de História da Universidade Federal de Viçosa.
} 
pesquisa documental mais sistemática, objeto da tese, contemplava os séculos XVI e XVII. De todo modo, vale notar que tais modificações se mostram fundamentais para a contextualização da pesquisa nos quadros do Império Português e da História da Igreja.

Parte dos acréscimos feitos pela autora é o resultado natural dos avanços de sua investigação após o término de sua tese, mas também, de seu esforço em proporcionar um texto de leitura mais fluida, cujo intuito é atingir um público leitor mais amplo, para além dos especialistas acadêmicos. Ambição louvável, sobretudo por colocar à disposição dos leitores o resultado de sólida pesquisa documental, visto que Patricia lança mão de amplo material; sejam impressos, pesquisados em bibliotecas do Brasil e de Portugal; sejam manuscritos, pesquisados fundamentalmente em arquivos portugueses. Além, vale observar, da ampla bibliografia arrolada pela autora, que pode servir de guia a novos investigadores, mas também a todos os interessados no assunto.

O intuito do livro de Patricia Souza de Faria é inquirir sobre o papel dos franciscanos na cristianização de Goa e, certamente, é esta sua maior contribuição historiográfica. Com efeito, para alcançar seu intento, a autora parte da premissa de que foram as articulações existentes entre o poder temporal e as instituições religiosas que definiram as circunstâncias mais propícias para a difusão do catolicismo em Goa. De modo que a conversão dos nativos goenses atende ao interesse da Cora portuguesa em garantir a fidelidade política desses novos súditos, compulsoriamente integrados ao reino católico. Sem dúvida, são estas articulações e os procedimentos adotados em face da necessidade da inclusão destes súditos, naturalmente diversos em termos religiosos, que estruturam os cinco capítulos de seu livro.

É possível traçar um percurso geral do livro, tendo em vista que ele nos remete à gênese da presença lusa na Índia, bem como ao papel desempenhado por Goa nesse amplo espaço, marcadamente heterogêneo. A partir disso, podemos acompanhar a estruturação dos poderes na região e a decorrente centralidade de Goa, onde a presença franciscana é mapeada pela autora em sua especificidade, tendo em vista as profundas divergências internas da Ordem. Por fim, o livro encerra-se com uma reflexão muito original e relevante a respeito dos sentidos atribuídos pelos frades franciscanos às suas missões. Proposição inovadora, uma vez que dissona das intepretações mais clássicas a respeito do papel histórico da Ordem na Época Moderna.

Assim, o que Patricia nos apresenta, é um eficiente histórico da consolidação da presença portuguesa em Goa, a primeira conquista lusa no Oriente. Com efeito, atenta para o caráter predominantemente mercantil que caracterizou o império asiático de Portugal, bem como a imprecisão dos limites do Estado da Índia até o momento em que a cidade passou a ser sede do poder civil e eclesiástico. Em suma, a autora evidencia o fato de que foi ali, primeiramente, o lugar onde a soberania lusa se firmou no Oriente. Tendo sido sede do vice- 
reinado e do arcebispado, Goa foi o centro do poder civil e eclesiástico, lugar onde funcionou o único tribunal inquisitorial em espaço ultramarino.

É nesta perspectiva que ao longo de todo o primeiro capítulo Patricia Faria sustenta ter a conquista espiritual amparado a expansão do Império Português, enquanto o poder secular favorecia a difusão do Evangelho. Daí que a presença de ordens religiosas como a Companhia de Jesus, a Ordem de São Domingos, a Ordem de Santo Agostinho e a Ordem de São Francisco sejam compreendidas como importante complemento da arquitetura dos poderes civil e eclesiástico estabelecidos na região. Enfim, é esse o contexto apresentado pela autora em sua exposição sobre as estratégias dos grupos sociais locais na manutenção de suas identidades de casta entre os convertidos, bem como a continuidade de crenças e relações sociais preexistentes.

Definido o pano de fundo de seu trabalho, o livro se detém nas ações adotadas pelo Arcebispado de Goa em face da necessidade de cristianizar as populações locais. Com efeito, tais procedimentos variam de acordo com o contexto. Ou seja, se num primeiro momento, ainda sob o cetro de D. Manuel, houve maior tolerância religiosa por parte do pequeno número de frades e clérigos que acompanhavam as embarcações que aportavam na cidade, a política religiosa tornou-se mais pragmática ao longo do reinado de D. João III, sobretudo a partir de 1540, quando tem inicio a destruição perpetrada por Miguel Vaz e Diogo da Borba aos pagodes brâmanes. Em suma, na perspectiva de Patricia Faria, paralelamente à tentativa de promoção sistemática do catolicismo em Goa, o que se verificou foi a intolerância e o afastamento progressivo dos nativos das altas esferas de poder no Estado da Índia, bem como dos cargos eclesiásticos de maior dignidade.

Nesse ponto, o livro estende sua análise e atravessa o período da União Ibérica. Com isso Patricia Souza de Faria não perde a oportunidade de nos apresentar o impacto da Monarquia Dual sobre a gestão dos assuntos eclesiásticos nas possessões portuguesas, período que foi marcado pela condução das populações cristianizadas à obediência da Igreja Romana. Todavia, com a União Ibérica, e principalmente após a ascensão de D. João IV, a Coroa portuguesa perderia espaço na região, notavelmente a partir da revisão das tradicionais concessões papais do Padroado levadas a efeito pela Propaganda Fide, o que definiu um novo contexto missionário na região.

Com efeito, estes diferentes contextos ganham contornos bem definidos quando Patricia Souza de Faria se atém especificamente ao papel dos franciscanos na conversão dos indianos ao catolicismo, notavelmente a partir da estabilização de uma rede paroquial nas Velhas Conquistas. Em suma, é rico o trabalho despendido pela autora na recuperação do rigoroso espírito de renuncia que tradicionalmente caracteriza os franciscanos, bem como seu impacto no interior da própria Ordem de São Francisco, com a estruturação de movimentos como o da Observância e seu êmulo da mais Estreita Observância. Por sua vez, tais movimentos, que traduzem divergências internas sobre o que seria o "verdadeiro 
franciscanismo", encontraram reverberação na Índia, onde se associam a outras controvérsias, como a luta pela condução institucional das custódias e províncias, ou a situação de conflito que se desenhou entre os franciscanos e os moradores de Goa, que acusavam os primeiros de infringirem lhes castigos corporais e prisões.

Definitivamente, é sua percepção do significado atribuído pelos próprios franciscanos à missão na Índia a maior contribuição do livro de Patricia Souza. A autora não apenas se debruça sobre uma ordem ainda pouco estudada, mas também procura superar algumas interpretações estereotipadas, que definem as missões franciscanas no Oriente como herdeiras de uma cosmovisão medieval, que impunha limites à compreensão de tradições e crenças locais, e teria comprometido o êxito missionário da Ordem. $O$ esforço de superação desses estereótipos conduz Patricia à percepção do horizonte de expectativa dos próprios franciscanos, em que noções como "êxito" e "fracasso" perdem sentido em face de suas concepções no que tange aos métodos de adaptação missionária, que é o elemento estruturante do sentido de missão partilhado pelos frades.

Com efeito, para alcançar este horizonte e acessar o sentido contextual destas missões, Faria se atém à escrita de sua história. Ou melhor, à quase total ausência deste gênero entre os frades franciscanos. De fato, a autora reconhece que, muito embora a Ordem de São Francisco tenha legado aos historiadores e pesquisadores uma profusão de escritos de cunho apologético e hagiográfico, elaborados principalmente ao longo da Idade Média, a ação da Ordem na Índia não ganhou espaço na produção historiográfica dos frades em um primeiro momento. A primeira crônica franciscana, de autoria de frei Francisco Negrão, foi escrita quase cem anos após a fixação da Ordem na Índia, contudo, esta obra se perdeu. Por sua vez, esta escassez de escritos torna-se mais marcante quando comparada à abundância da produção jesuíta, bem como as reconhecidas implicações de seu uso na confecção da propaganda inaciana. Na perspectiva da autora, esta característica circunscreve a especificidade do apostolado franciscano, que privilegiava as formas orais para o testemunho de seu ministério. Um ministério cujo sentido apoiava-se na graça e no fervor religioso, mas que, todavia, estava destinado à obsolescência, tal como sugere a autora.

De todo modo, o livro enfrenta a questão da construção da memória franciscana e nos apresenta um rico debate a respeito deste assunto. Para isso, Patricia Souza de Faria recupera os escritos de três autores que se detiveram sobre a Ordem: frei Paulo da Trindade, que exalta os feitos dos frades da Regular Observância; frei Jacinto de Deus, que registra a história dos franciscanos da mais Estreita Observância; e frei Miguel da Purificação, que por sua vez reclama o direito dos religiosos filhos de portugueses nascidos na Índia ocuparem cargos eclesiásticos. A despeito da especificidade de cada um dos autores, todos estes frades procuram reabilitar e exaltar os feitos dos franciscanos, sobretudo a partir da ratificação do pioneirismo e da vocação missionária da Ordem. Com efeito, na perspectiva de Patricia, a existência desta literatura, produzida a partir da primeira metade do século XVII, é um 
indício seguro da necessidade de se evidenciar a capacidade de atuação da Ordem de São Francisco Índia.

Entretanto, para além das narrativas, Patricia Faria atenta para as diferentes trajetórias de vida de seus autores, tendo em vista questões relevantes, referentes aos sentidos da pureza de sangue e distinção social, que se desdobram dos embates polêmicos a respeito da origem dos clérigos, apresentados nas obras de autoria dos franciscanos, notavelmente na de Miguel da Purificação. Em suma, vale lembrar que todos estes religiosos são lusodescendentes e apresentam uma perspectiva depreciativa do Oriente, sendo que Trindade concebia a si mesmo tão português quanto qualquer outro nascido no reino, ao passo que Jacinto de Deus e Miguel da Purificação enfrentaram com maior vigor o fato de terem nascido na Ásia, e por isso compartilhavam a preocupação de reforçar sua distinção em relação aos demais grupos de nativos.

Em conclusão, o que se nota é a lenta estruturação de uma duradoura marginalização do clero nativo, uma vez que somente em 1927 um goense viria ocupar o arcebispado. Por fim, é imprescindível assinalar que Patricia Souza de Faria nos apresenta uma obra de fôlego, resultante de inquietações epistemológicas originais, bem como da leitura, análise e confrontação de fontes. Daí que o livro nos chega em bom momento. 